\title{
CONTRACTORS' HSE PERFORMANCE: PRAGMATIC EVALUATION, BENCHMARKING AND WAYS FOR IMPROVEMENT
}

AHMED M. QABAZARD, BALA SIVA SRIKANTH ADIVI \& AJAY K. MOHANTY

Health, Safety \& Environment (West Kuwait) Team, Kuwait Oil Company, Kuwait

\begin{abstract}
Improvements to contractors' HSE standards can be ensured by continuous monitoring and review of their HSE performance. To achieve this, an objective HSE Performance Evaluation (HPE) framework is necessary and essential. Although there are various conventional methods of HSE performance evaluation available in the industry, however, a more comprehensive HPE framework with pertinent HSE parameters will aid to the monitoring approach. In line with this, a more comprehensive HPE framework, which takes into account all HSE parameters pertinent to a contracting organization and its project, has been developed and followed at West Kuwait Directorate (one of three main important assets of Kuwait Oil Company-KOC). This gives better insight and Subject Matter Experts (SME's) of the organization do appropriate and effective professional outcome out of it. In this project (HSE Performance Evaluation), the pertinent factors are analyzed critically, recorded the compliance and deviations w.r.t. the applicable procedures / standards, prepared "SWOT analysis" and suggested the appropriate recommendations appropriate to the risk-based gaps besides benchmarking. This analytical framework of HSE Performance Evaluation (HPE) model can be applied for all contracting agencies, which would facilitate the benchmarking process.

Keywords: HSE Performance Evaluation, HPE framework, HSE Management System Performance, Critical risk-based gaps, SWOT models.
\end{abstract}

\section{INTRODUCTION}

Role of Contractors in industrial development especially in oils sectors are very vital. Industrial sector cannot develop with the current growing demand without the assistance of proper contracting agencies. The contractors are key players in the sustainable oil sector projects from predesign and design, through construction and project closeout. They also provide immense supports in operation and maintenance of our production facilities also. But in this context a question arise in our mind that, how do the performance (especially on HSE compliance) of any contractor is monitored effectively? Kuwait Oil Company (KOC), Kuwait HSE Management System [1] and related HSEMS procedures [2], prescribe some of the monitoring process to ensure HSE compliance/performance [3], (Fig. 1) of the contractors through SVV, audits, etc. In order to bring the effectiveness of these monitoring tools, KOC, HSE-West Kuwait (WK) team thought it critically and develop a pragmatic method of HSE Performance Evaluation (HPE), (Fig. 3) framework for all contractors working under WK Directorate. It is not only an analysis, but also goes beyond doing the analytical study of the strength, weakness, with prevailing threats and available opportunities for each contractors and suggest remedial measures for improvement.

The comprehensive analytical framework is an effective tool that utilizes critical inspection databases (SVV, Work Site, Site Office and MyHSSE [4], data) to measure the overall Contractor's compliance on KOC HSE Management System [1], HSEMS Procedures [2]/Standards implementation at contractors' work sites and their site offices. This is invariably required to have a safe and successful operating journey between Kuwait Oil Company and Contractor. 


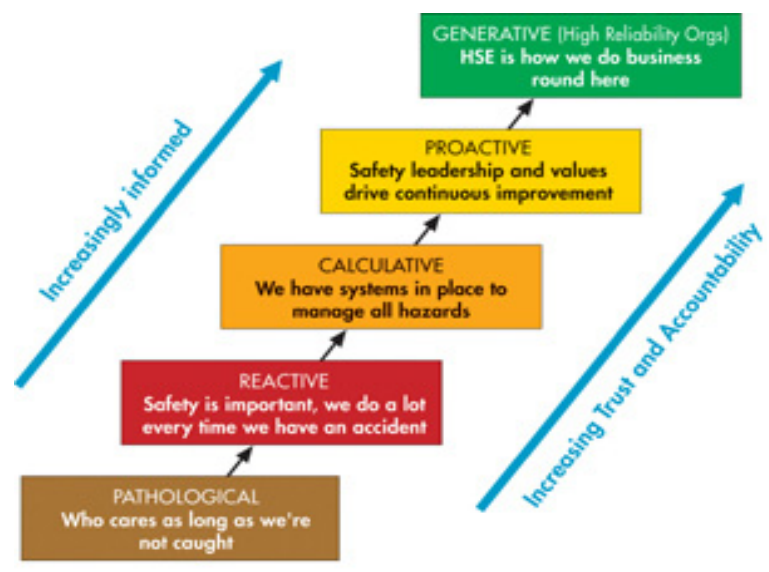

Figure 1: HSE performance scale.

\section{NECESSITY}

Globally it is acknowledged that an improved HSE compliance implementation through risk based gap analysis has direct and proactive bearings on functional and operating safety standards of the facilities in general and productivity in particular.

\section{OBJECTIVE}

The purpose of this analytical and benchmarking tool is to evaluate the HSE performance (Fig. 1) of WK-based contractors by reviewing their level of HSE management systems compliance, policies, statistical performance, adherence to standards, etc. The performance gaps and positive observations identified through this analysis were used as a basis for the analysis and resultant recommendations, in order to improve upon HSEMS procedural compliance and by extension of HSE performance (Fig. 1) of WK contractors' workforce [3].

The long-term intent is to build a project findings to document best practices, lessons learned, and examples of various documents to benefit KOC and the Contractors in terms of benchmarking, evaluation \& enhancing HSEMS performances.

\section{METHODOLOGY ADOPTED}

The above evaluation process is unique and different from various conventional methods, which focuses not only on level of implementation but also causes of deviations. The following steps are involved in the above process:

- To develop a comprehensive analytical tool / framework utilizing various inspection databases such as

- HSE Inspections @ worksites

- Observations from Site Verification Visits (SVV's)

- HSE Inspections @ Site Offices

- Other HSE Leading and Lagging Indicator performance from MyHSSE [4], data

The above parameters are selected to measure the overall Contractor HSE Performance (Fig. 1) on KOC HSEMS procedures/Standard compliance [2]. 
- Evaluate HSEMS procedural/ Standards implementation and compliances based on the risk level at Work Sites \& Site Offices of all KOC West Kuwait Contractors.

- Identification and Analysis of Positive observations/Compliance on KOC HSEMS Procedures/Standards [2].

- Identification and Analysis of critical risk based gaps/ non-compliance of HSEMS procedures/Standards [2].

- Benchmarking the HSEMS Procedures/Standards performance compliances for all WK Contractors.

- Sharing Results/Contractor Performance status with respective Controlling Teams to improve Contractor Performance. [3].

- Closely follow-up with the respective Contractor through the Controlling Team for tracking and closure of the opportunities of improvement (OFI's).

\section{EVALUATION PROCESS}

The evaluation of the above parameters was done systematically for a period of four years (in the phased manner) in the following way:

5.1 Establishing and maintaining a contractor HSEMS performance compliance analysis (Fig. 3) and benchmarking program

This has been made with defined strategic HSEMS Performance Evaluation Criteria based on established KOC Risk Assessment Procedures

5.2 Collecting and storing observation data to assess and analyze performance

Input has been taken from the following parameters

- Determining Data Needs ( MyHSSE [4], SVV, Worksite \& inspection data)

- Data storing requirements.( segregation of clause wise \& risk based observations)

- $\quad$ Risk rating on individual observations as per KOC risk matrixes

5.3 Analyzing, reviewing, and finalizing performance data

Three-step process has been established as follows:

- Step 1: Critical review and analysis of observations

- Step 2: Develop individual Charts for different HSEMS procedures/Standards.

- Step 3: Recommendations based on the individual chart analysis

\subsection{Performing SWOT analysis (Fig. 2)}

A SWOT analysis (Fig. 2) (alternatively SWOT matrix) is a structured planning method used to evaluate the Strengths, Weaknesses, Opportunities and Threats involved in a project or in a business venture. We have made an effort to utilize SWOT (Fig. 2) model for identification of effective contractors' HSE Management System Strategies.

The study has been made methodically to identify and analyze internal factors (strengths and weaknesses) and external factors (opportunities and threats) of the contractors. Subsequently, by means of the SWOT model (Fig. 2), the identification of all internal and external factors 


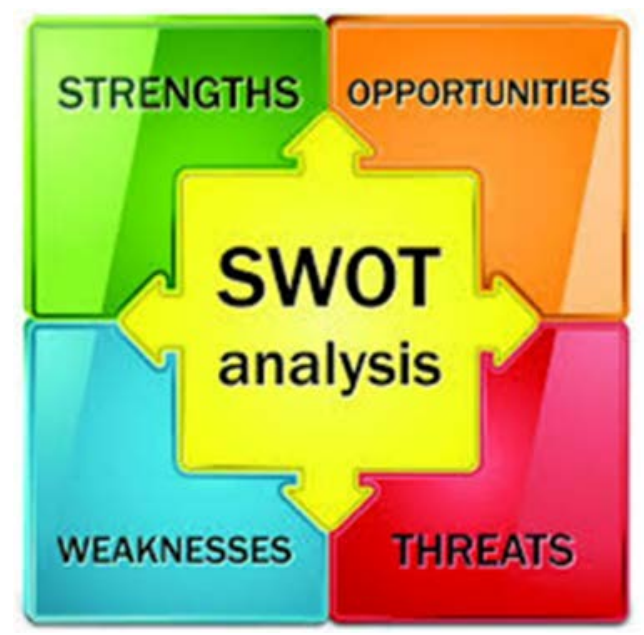

Figure 2: SWOT Model.

are made for evaluation of proper strategies in order to enhance opportunities and strengths and analyze the weaknesses and threats.

5.5 Using performance information to drive improvement

Three-step process has been established as follows, which involves critical component i.e. communicating the results to the Controlling Team(s).

- Step 1: Communicate "Contractor Performance Report [3]" to the respective Controlling Teams.

- Step2: Organize meeting with Controlling Team to explain the evaluating process and the expected improvement action plan on the recommendations.

- Step 3: Follow up on the recommendations and action plans to close the gap during Monthly Contractor Meetings.

5.6 The process of annual analysis (Fig. 3)

\subsubsection{Phase I and Phase II (Table 1)}

Each the above phase involves the following steps:

- Systematic building of databases for site-checked SVV's, Leadership HSE Visits, construction/project worksites, site offices inspections and 'MyHSSE [4]' reports.

- Selection of HSEMS performance [3], parameters and criteria (i.e. SVV elements, leading/lagging indicators from MyHSSE[4], HSEMS application standards as per Scope of Work, Permit to Work procedures and other applicable KOC HSEMS procedures[2] and standards

- Thorough review and analysis of such databases, including SWOT (Fig. 2) analysis (Strength-Weakness-Opportunities-Threat) of performance levels, results from the generated site reports. 
- $\quad$ Risk ranking of resultant performance gaps, in accordance with KOC HSEMS Risk assessment procedures.

- Identify the performance - gaps and positive observations, and develop individual and dedicated analytical charts of the same.

- Brainstorm to list - thorough analysis, specific remedial recommendations to close/improve non-compliance and performance gaps.

- Communicate the Contractor's performance reports and recommendations to the respective KOC Controlling Teams, to initiate and arrange for the necessary corrective and improvement actions.

- Share the recommendations and positive observations with the respective contractors during one-to-one meetings or during Monthly HSE Contractors meetings.

- Track the improvement recommendations compliance action plans to close the identified gaps.

5.6.2 Phase I: HSEMS Performance [3], Compliance Analysis (Fig. 1), (Fig. 3) for the duration (Dec 2013 to June 2014), (Table 1).

5.6.3 Phase II: HSEMS Performance[3] Compliance Analysis (Fig. 1), (Fig. 3) for the duration (July 2014 to Jan 2015) (Table 1).

5.6.4 Phase III: The comparison process-evaluation between both Phase I and Phase II and HSEMS Performance[3] Compliance Analysis (Fig. 1), (Fig. 3) for the duration (April 2015 to Dec 2015), (Table 1).

5.6.5 Phase III involves the following steps/process: (Table 1)

- Comparison of HSEMS procedures performance [3], parameters compliance levels of phase II and I

- Identify the common/repeated site-observations in both phases, in addition to the improving and declining performance compliance levels and parameters

- Analyze related performance charts for gaps and positive observations' variations and trends.

- Evaluate related risk levels in declining performance gaps.

- Brainstorm to list conclusion and remedial recommendations, in accordance with each chart and its analysis separately.

- Communicate the Contractor's performance reports and recommendations to the respective KOC Controlling Teams, to initiate and arrange for the necessary corrective and improvement actions.

- Share the recommendations and positive observations with the respective contractors during one-to-one meetings or during Monthly HSE Contractors meetings.

5.6.6 Phase IV: HSEMS performance [3] compliance analysis for the duration (April 2016 to Dec 2016), (Table 1).

All the above phases and nos. of contractors that were evaluated in each phase are listed below: 
Table 1: Phase wise analysis data.

\begin{tabular}{|c|c|c|c|}
\hline Phases & Period & $\begin{array}{c}\text { No. of } \\
\text { Contractors } \\
\text { evaluated }\end{array}$ & Details \\
\hline Phase I & $\begin{array}{c}\text { December 2013- } \\
\text { June 2014 }\end{array}$ & 17 & $\begin{array}{c}\text { Contractor HSE Performance } \\
\text { Compliance Analysis }\end{array}$ \\
\hline Phase II & $\begin{array}{c}\text { July 2014-January } \\
2015\end{array}$ & 13 & $\begin{array}{c}\text { Contractor HSE Performance } \\
\text { Compliance Analysis }\end{array}$ \\
\hline Comparison I & $\begin{array}{c}\text { December 2013- } \\
\text { January 2015 }\end{array}$ & 12 & Comparison Analysis \\
\hline Phase III & $\begin{array}{c}\text { April 2015- } \\
\text { December 2015 }\end{array}$ & 15 & $\begin{array}{c}\text { Contractor HSE Performance } \\
\text { Compliance Analysis }\end{array}$ \\
\hline $\begin{array}{c}\text { Comparison } \\
\text { II }\end{array}$ & $\begin{array}{c}\text { July 2014- } \\
\text { December 2015 }\end{array}$ & 11 & \begin{tabular}{c} 
Comparison Analysis \\
\hline Phase IV
\end{tabular} \\
$\begin{array}{c}\text { April 2016- } \\
\text { December 2016 }\end{array}$ & 19 & $\begin{array}{c}\text { Contractor HSE Performance } \\
\text { Compliance Analysis }\end{array}$ \\
\hline
\end{tabular}

\section{DATA OBTAINED FROM "MyHSSE [4]"}

"MyHSSE [4]" Reporting System is a Web Based Performance Monitoring Tool for Health Safety, Security and Environment at Kuwait Oil Company (KOC). This software being used by KOC to report, record and track HSE measures such as Incidents, Near Miss reports, Hazardous conditions, SOC (Safety Observations and Conversations), SVVs (Site Verification Visits) of CAEs/ NCAEs etc.

The following data of various contractors is taken from 'MyHSSE [4].

Table 2: Input taken from 'MyHSSE' [4].

\begin{tabular}{|l|l}
\hline Lagging Indicators & $\begin{array}{l}\text { Lost Work Day Case, Industrial Non-Disabling Injury } \\
\text { Incidents, Property ( Asset) Damage Incidents , Fire } \\
\text { Incidents, Motor Vehicle Accidents (MVA's) }\end{array}$ \\
\hline Leading Indicators & Near Miss Incidents, No of Speed Violations
\end{tabular}

\section{RESULTS GAINED AND ADVANTAGES}

- Zero Lost Workday Cases ( of Contractors) in WK Fields since May 2013.

- Provided a mechanism for Risk based performance reporting on Contractors HSE compliance to the Controlling Teams and Contractors Management.

- Performance of WK Contractors is benchmarked, which is utilized to enhance their Performance compliances.

- Benchmarking encourages healthy competition amongst WK Contractors to strive for better HSE Performance [3] (Fig. 1).

- Positive procedural compliances has increased substantially, which resulted in positive HSE statistics for WK fields. 
7.1 Evaluation process structure

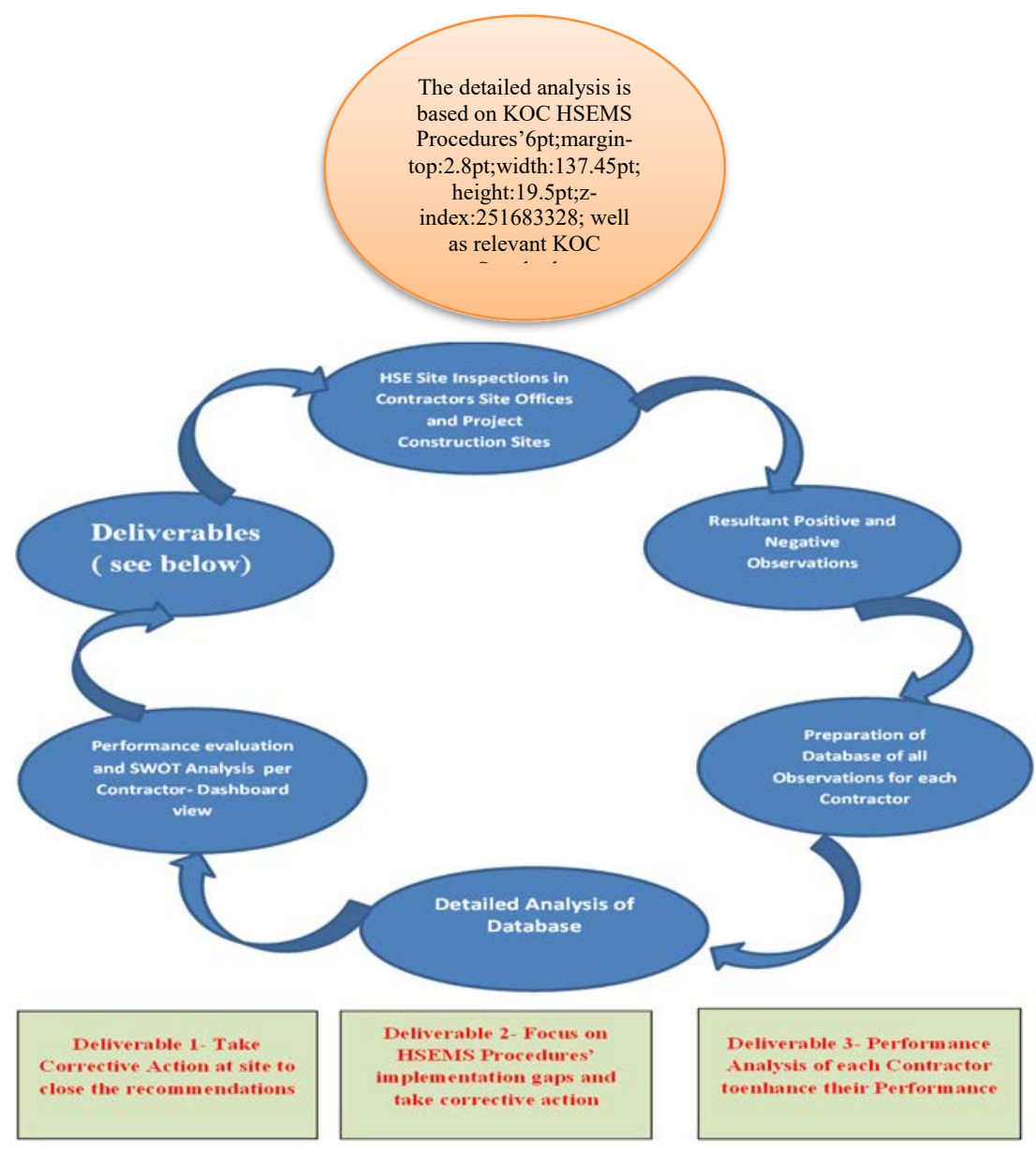

Figure 3: Performance evaluation flowchart.

- Provides a platform for the Controlling Team to effectively monitor Contractor HSE performance [3] (Fig. 1) compliance level.

- Effective Tool for competent workforce hiring, promotions, work assignments, rewards/penalties of Contractors.

- Provides a structured approach focusing on contractors' Strategic Performance objectives.

- Transfer best practices across other KOC Directorates for improving Contractor HSEMS compliance performance [3], (Fig. 1). 


\section{CONCLUSION}

"Contractor's HSE Performance: Pragmatic Evaluation, Benchmarking and Path to Improvement" is a practical approach to assess, evaluate the HSE performance of contractors by reviewing their compliance-level to KOC HSEMS Implementation Procedures [2] and standards. The performance gaps and positive observations identified through this analysis are used as a basis for the analysis and resultant recommendations, in order to improve upon HSEMS procedural compliance and by extension of HSE performance [3] (Fig. 1) of West Kuwait contractors' workforce. This analysis not only provides a practical approach for measuring HSE performance to a high accuracy level but also offers guidance on developing a benchmark of HSE performance measures relevant to the organization.

The long-term intent is to build a project findings to document best practices, lessons learned, and examples of various documents to benefit KOC and the Contractors in terms of benchmarking, evaluation (Fig. 3) and enhancing HSEMS performance (Fig. 1). This kind of initiative clearly signify organization's commitment "We Care".

\section{REFERENCES}

[1] KOC HSE Management System Guide.

[2] KOC HSE Management System (HSEMS) Procedures.

[3] KOC HSEMS Performance Reports of Contractors.

[4] KOC 'MyHSSE' Data. 